\title{
Characteristic of Evaluation in Learning Arabic Language at Islamic Boarding School Anwarul Huda Malang
}

\section{Alsuna: Journal of Arabic and English Language}

\section{Ahmad Jaunanto \\ Universitas Negeri Malang \\ @ jaunanto07@gmail.com \\ Hanik Mahliatussikah \\ Universitas Negeri Malang \\ @ hanik.mahliatussikah.fs@um.ac.id}

\section{Keywords:}

Learning Arabic

Measurement

Assessment

Evaluation

\section{Article Information:}

Submitted: 29 May, 2020

Accepted: 13 November, 2020

Approved: 25 November, 2020

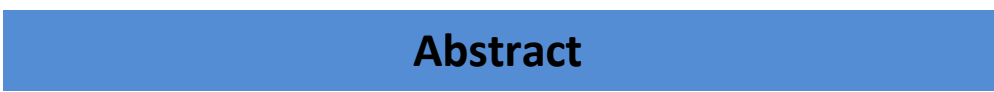

Purpose - This study aims to describe the evaluation of Arabic language learning at boarding school Anwarul Huda Malang.

Design/methodology/approach - This study used is qualitative research, and the data of this study are the teachers who teach in islamic boarding school Anwarul Huda Malang and the method of data collection using interview and observation.

Findings - The study describe the evaluation of the Arabic learning assessment at the Anwar Al-Huda Malang Institute which was carried out twice, namely the midterm and final semester exams. The first form of the exam is by reading a book in midterm, and the finally is by filling out an answer sheet, namely a written exam. The evaluation tools used are multiple test questions, true and false questions, and short answer test questions.

Originality/value - Learning evaluation should be continuity. This means that if it is tested at the beginning by reading a book, it should also end by reading a book. It is enough that the question points need to be changed.

Paper type - Research Paper

المقدمة

يتمّ تعليم اللغة العربية في إندونيسيا منذ فترة طويلة, في المدارس الرسمية وغير الرسمياة, من المدرسة الابتدائية حتى الجامعة. لأن اللغة العربية مهمّة جدا لدى المجتمع الإندونيسي, هي كاللغة الدينيةة, والشقافياة, والعلمياة, والتواصلية مع العرابيين (2018 Ridho). دروس اللغة العربية في المعاهد الإسلامية والمدارس الإسلامية كالدروس الأسـاسية منذ تأسيسها. وكذلك اللغة العربية في المعاهد السلفية كاللغة الأسـاسية في التعليم, لأنّ كتب مستحدمة كلها باللغة العربية. التركيز في التعليم قواعد النحو والصرف, لأنّ هذان كالآلات لقراءة الكتب المستحدمة. ويمثل التقويم أحد المداخل الحديثة لتطوير التربية أو التعليم, فمن خلاله يتم التعريف على أثر كل ما تم التخطيط لله وتنفيذه من عمليات التربية أو التعليم, ونقاط القوة والضعف فيها, و من ثم إقتراح الحلول التي تساهم في التأكيد على نقاط القوة وتدعيمها, وتتلافي مواطن الضعف وعلاجها. التقويم يستطيع 
Page $\mid 180$

أن يدافع المتعلّمين ليكونوا الناشطين في التعلّم وكذلك يدافع المعلّمين ليحسّنوا عملية التعليم ويدافع

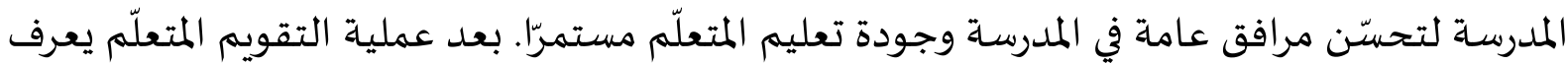
كفائته في التعلّم والمعلم يستطيع أن يختار طريقة التعليم و وسـائل التعليم الجيدة, لأن التعويم يبحث كلّ شيء في التعليم. التقويم هو عملية منظمة لمعرفة دراجة شيء (شرط, نشاط, عملية, حكم, فاعل, ومفعول, وما أشبـه ذلك) بناء على المعيار المعيّن عن طريق التقييم (Mahirah B 2017). التقويم في المعهد مهّم جدا لأن المعهد من مؤسسات تعليمياة، وكل مؤسساة تعليمية تختاج إلى التقويم لنظرة نجاح عملية التعليم فيها. ولكن التقويم فياء يختلف بالتقويم في المدرسـة العامة. أغراض التقويم أربعة هي (1) معرفة نجاح العملية التربوية والعملية التعليمية في المدرسة. عن لمن طريق التقويم سوف نعرف نجاح المتعلم من الجوانب الأكاديمية, و الاجتماعية، والعاطفية، والأخلاقية، والمهارة في تحقيق الأهداف التعليمية التي تمّ تحديدها. (r) إعطاء المساءلة من المدرسة لأطراف المعينة،

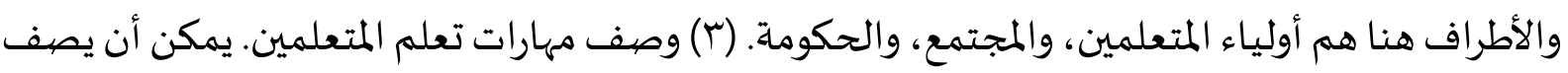
التقويم مهارات التعلمالموجودة لدى المتعلمين حتى يمكن رؤية نقاط القوية والضعف لدئه لديهم في كلّ المواد التعلمية. (ع) تحديد متابعة نتلئج التقويم. يتم ذلك من خلال التحسينات وتكميلات من حيث برامج التعلم

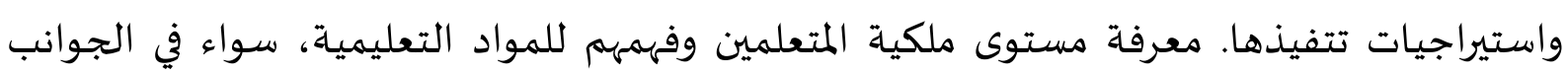

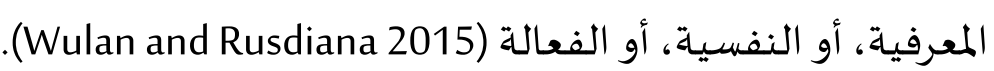
التقويم أربعة أنواع هي: () التقويم التشخيصي: هو نمط مل انماط التوقعات، يتيح للمدرس اوس معرفة ما إذا كان المتعلم قادرا على تتبع الأنشطة المنتظر إنجازها .في الأسبوع الاول من السنة الدراسية، ينظم المدرس أنشطة تقويمية ليتعرف المستوى المعرفي والمهارة لتلاميذه .كما يلجأ المدرس إلى التقويم التشخيصي عند بداية كل درس للوقوف على مدى تحكم المتعلمين في التعلمات. r ) التكويني: يهدف إلى فحص مدى تمكن المتعلم من تحصيله، كما يتيح للمدرس اكتشاف مواطن الصعوبات، فيقوم بسد مدائ الثغرات. ب) الإجمالي :يهدف إلى فحص حصيلة التعلم واختبارها في نهاية كل وحدة دراسية لاتخاذ القرارات،

ع) الذاتي :هو تقويم التلميذ تعلماته وتحصيله بنفسـه، مما يحفزه للاستزادة من التحصيل. يذكر منى أن هناك أدوات مختلفة يتم عمل التقويم من خلالها، ويعتمد اختيار الأداة المناسبة على

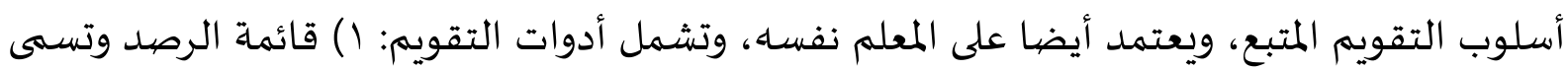
أيضا قائمة الشطب: وهي عبارة عن قائمة بأفعال أو سلوكيات يرصدها المها المعلم أثناء تنفيذ مهمة تعليمية

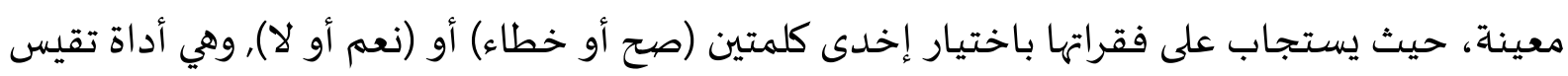

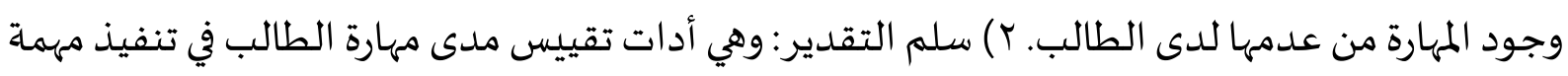
معيّنة أو مقدار ما اكتسـابه من مهارة معيّنة، فهي تشبه قائماة الأفعال والسلوكات التي في قائمة الرصيد,

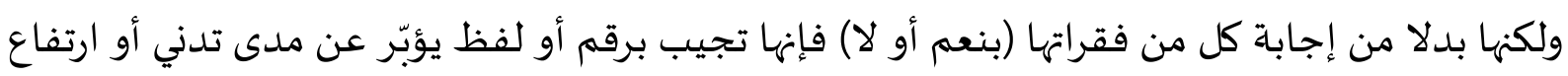

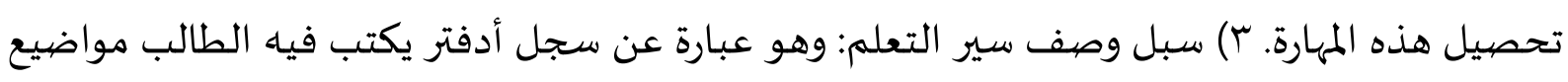

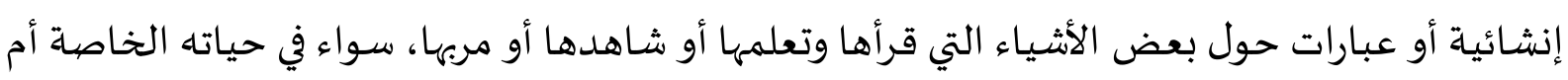


في الفصل، ويمكن التعبير عن آرائه بحرية في في هذا السجل، وهو يعد بذلك استراتيجية لمراجعة الذات حيث يحتفظ الطالب بالسجل معاه، ويجمع المعلم السجلات من الطلبة كل فترة بشكل دوريّ حتى يقرأها ويعلّق عليها بشكل إيجابي وبنّاء، وبالتالي تقويمهم بشكل أدق. ع) السجل القصصي: وهو يشباء إلى حد ما سجل وصف سير التعلم، ولكناه سجل يحتفظ باء المعلم (ويكون لدياء سجل خاص منفرد لكل طالب).

Page | ويسجل فياء ما يفعله الطالب والحالة التي تمت عندها الملاحظة، ويحتوي السجل على ملاحظات المعلم عن 181 سلوك الطالب وفروضها المدرسية وملاحظاته عن الأنماط المتكرّرة لدياء مبيّنة بالمكان والتاريخ، ويتم تسجيل

الأحداث فياه بطريقة وصفية.

\begin{tabular}{|c|c|c|c|}
\hline الذاتي & الإجمالي & التكويني & التشخيهي \\
\hline قائمة التقويم الذاتي & إلمامتحانات الموحيدة المستمرة & 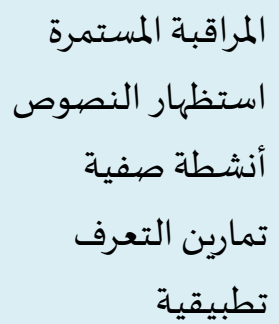 & وضئلية إدماجية \\
\hline
\end{tabular}

طريقة البحث

كانت الطريقة المستخدمة في هذا البحث هي البحث الوصفي. اختار هذه الطريقة لأن أهداف هذا

البحث وصف التقويم في اللغة العربية في معهد أنوار الهدى. وفقال krippendorff في (Moh. Ainin 2007) أناه قال تحليل المحتوى هو تقنية بحث لصنع الاستنتاجات من خلال تحديد الخصيائص المحددة بشكل منهجي وموضوعي في النص. أي هذا البحث النوعي وصف أحوال التي يتعلق بموضوع البحث. وحجة اختيار هذا البحث لأن هذا البحث يبين نتائجالبحث عن الطريق الإجرائية على التقويم في اللغة الهربية في معهد أنوار الهدى. البيانات هذا البحث هي المعلّمون الذين يعلّون في معهد أنوار الهدى وطريقة جمع البيانات هي الملاحضية والمقابلة.

\section{المناقشة}

تعليم اللغة العربية في معهد أنوار الهدى مالانج له أهداف كثيرة منها: لضرورة العبادة، نحو

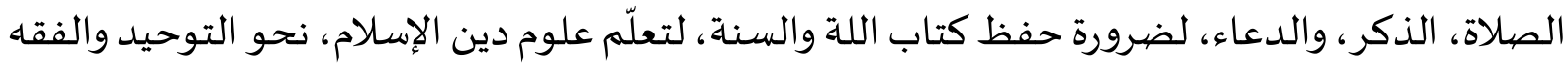
والتساوف وغير ذلك.

في أول تعليم اللغة العربية في إندونسيا لضرورة العبادة فقط كالصلاة والدعاء والذكر ولتقرّب إلى اللعة تعالى. ولكن بعد مرور الزمان تطوّر اللغة العربية كوسيلة لفهم مصادر الأحكام الشرعية وتعلم دين الإسلام كالقرآن والأحاديث النبوية والكتاب باللغة العربية الأخرى (Tolinggi 2020). المعهد يركّز تعليمه إلى مونى 
اللغة العربية لتكون وسيلة في فهم القرآن والحديث والكتب التراثية حتى تعليم اللغة العربية أكثر من العلوم الأخرى (Oktavera 2019).

تعليم اللغى العبربية في معهد أنوار الهدى يستخدم طرق كثيرة منها: حفظ القواعد قاعدة النحو والصرف عن طريق حفظ بعض الكتب نحو نظم الجرومية ونظم العمريطي ونظم الألفية والأمثلة Page | التصريفية وغير ذلك. تعليم اللغاة العربية في المعهد السلفي يركز على تعليم القواعد اللغوية مثل النحو 182 والصرف والبلاغة بحفظ المصطلاحات النحوية والصرفية وحفظ الأنظمة التي تتعلق بالقواعد اللغة العربية (Asy'ari and Zainuddin 2018). طريقة باندوعان، في طريقة باندوعان يتوجاه الطلاب كلهم المعلم ويقراً المعلم الكتاب ثم يكتبه الطلاب ويفهمون معناه. وهي طريقة تعلّم الكتاب التراثي التي يتبعه الطلاب جماعـة. يجلس الطلاب حول المعلّم الذي يقرأ الكتاب (Chairi 2019). طريقة صاراجان، الطلاب يحملون كتبهم ويتوجهون المعلّم واحدا فواحدا. بعد ذلك يقرأ المعلّم الكتاب. في طريقة صاراجان يتوجه الطلاب المعلّم واحدا فواحدا من حلال حمل كتههم. المعلم يقرأ الكتاب (Mu'izzuddin, Juhji, and Hasbullah والطاب يكرّرون قراءته حتى قادرون قراءة ذلك الكتاب وفههم معناه

طريقة التشاور، في معهد أنوار الهدى هذه الطريقة تستخدم للمرحلة النهائية أو السـادسة في مادة النحو. في هذه الطريقة المعلم يرشد طلابها ليبحث في مادته. وهدفه لتمرين الطلاب في حلّ المشكلات في المادة

(Rohman 2017)

معهد أنوار الهدى يستخدم الكتب التراثية كوسائل التعليم. مادة الدين التي يتعلمها الطلاب معخوذة من الكتب التراثية أو كتب الأصفر التي يألفها العلماء القدماء. تسمى بكتب الأصفر لأن لون كرطاسها أصفر لو كان الآن تطبق بالقرطاس أبيض اللون. كتاب أصفر يسمى أيضا بكتاب تراثي .(Thoriqussu'ud 2012) أهداف التقويم في تعليم اللغة العربية في معهد أنوار الهدى نوعان هدف العام وهدف الخاص، أما هدف العام هي لمعرفة فعالية عملية التعليم، وأما أهداف الخاص منها: لمعرفة كفاءة الطلاب في قراءة الكتب التراثية وعلوم الدين و فهم اللغة العربية، لمعرفة فعالية استراتجية التعليم التي يستخدمها المعلم نضرا من طريقة ووسائل، لمعرفة الصعوبات التي يشعرها المتعلم ومن هذه يمكن للملعم أن يطور الكتاب المستخدم، لمعرفة ضعف الطلاب وقوته في حفظ المادة.

أغراض التقويم نوعان غرض عام وغرض خاص، أما غرض عام هو لمعرفة فعالية التعليم. معشّرات فعالية التقويم يعرف من تغيّر سلوك المتعلّم. هل سلوك متعلّم بناء على كفاءة، وأهداف، ومنهاج

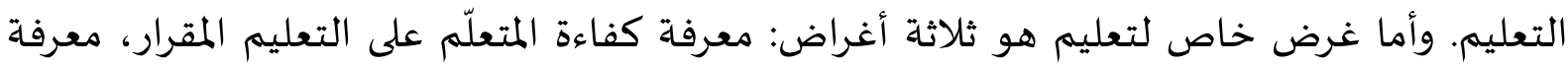
الصعوبات يشعرها المتعلّم حتى يستطيع معلّم أن يعالجها ويعطي تكرار التعليم، معرفة فعالية استيراجية التعليم التي يستخدمها المعلّم, نضرا من طريقة, ووسائل, ومادة التعليم. 
Page | $183 \quad$ الأخلاقياة، والمهارة في تحقيق الأهداف التعليمية التي تمّ تحديدها. (Y) إعطاء المساءلة من المدرسة لأطراف المعيناة، والأطراف هنا هم أولياء المتعلمين، والمجتمع، والحكومة. (Y) وصهف مهارات تعلم المتعلمين. يمكن أن يصف التقويم مهارات التعلمالموجودة لدى المتعلمين حتى يمكن رؤية نقاط القوية والضعف لديهم في كلّ المواد التعلمياة. (ع) تحديد متابعة نتلئج التقويم. يتم ذلك من خلال التحسينات وتكميلات من حيث برامج

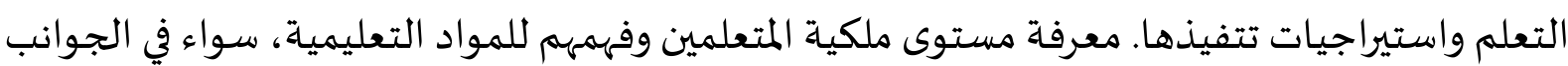
المعرفية، أو النفسية،، أو الفعالة (Wulan and Rusdiana 2015).

\section{طريقة التقويم في المعهد وأدو اته}

يقوم التقويم في المعهد السلفي كالمدرسة عامةة يعني مرتين في سنة واحدة. ولكل فصل دراسي تقوم عملية مقدار القيمة أو التقدير عن طريق الاختبار مرتين في كلّ نصف الفصل الدراسي. ولكنّ هناك خصائص في هذه العملية. الاختبار لنصف الفصل الدراسي ليس بإعطاء ورقة الاختبار بل بقراءة الكتب منب مئب المستخدمة،, ثمّ ما السؤال؟ السؤال في جودة القراءة, وفهم النص, والقواعد النحوية أو الصرفية. ولكن هذه العملية تحتاج إلى أوقات طويلة حتى يقوم الاختبار عن الطريق مختلفة من مادة واحدة والآخر.

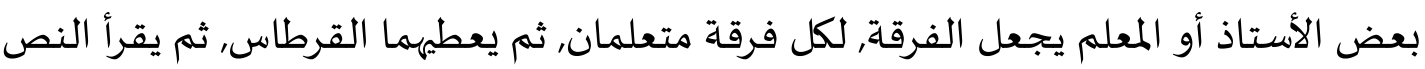
على أقل باب واحد, ثم هما الذي يعطي النتيجـة بعضها بعضا. وبعض الأستاذ يأمر المتعلمين أن يقرؤوا

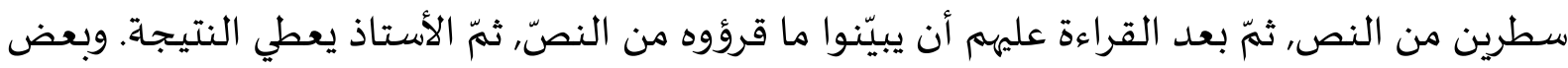

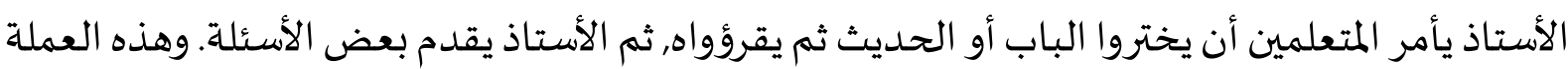

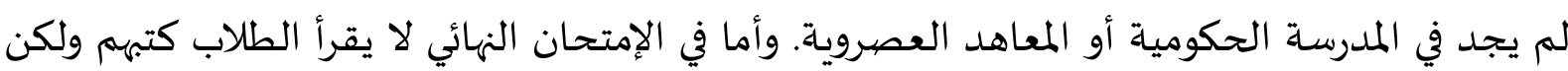
الإمتحان يجري كمثل الإمتحان في المدرسة كالعادة. أي الطلاب يجيبون الأسئلة في ورقة الإجابة. والأسئلة

$$
\text { تتكون الإختبارات الموضوعية. }
$$

الوسائط أو الأدوات هي شيء يمكن استخدامهاء لتسهيل تنفيذ المهام أو تحقيق الأهداف بفعالية وكفاءة على شخص ما. يشار إلى كلمة "أداة" بشكل شـائع باسم "أداة". وبالتالي يمكن أيضًا الإشارة إلى أداة /

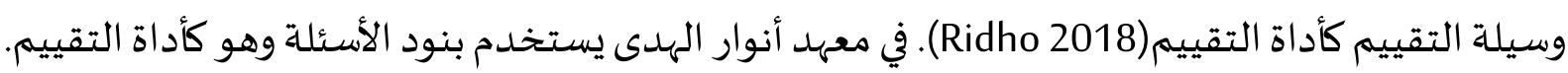
أما الإختبار لهذا التقييم هي الإختبار الموضيوعي. الإختبار الموضوع أنوع كثيرة ولكن في هذا المعهد يستخدم ثلث أنواع الإختبار وهي: ( ) الإختبار من متعدد، ويعد هذا النوع من أصعب الاختبارات الموضوعياة حين صياغتاه وبنائه وتقنينه إلا أنه أسهلها لمتيا تصحيحا وإجراء (Muhammad Abd al-Khāliq 1996). †) اختبار الصيواب والخطأ، يختار الطلاب الإجابة بين الصواب والخطاء وهذا الإختبار من الإختبار الموضوعي. ويستخدم هذا الإختبار فقط في مادة الفقه. ب) 
الإختبار بالإجابة الموجزة، هذا الإختبار من الإختبار الموضوعي. وفي معهد أنوار الهدى يستخدم هذا الإختبار وأحيانا عدد بنوده خمس بنود وهذه وقعت بعد بنود الإختبار من متعدد.

الخلاصة

تعليم اللغة العبية في معهد أنوار الهدى لله ثلاثة أعراض وهي لضرورة العبادة، ولضرورة حفظ

كتاب اللة والسنة، ولتعلّم علوم دين الإسلام. ولتعليمها تستخدم عدة الطرق وهي حفظ القواعد قاعدة النحو والصرف، وطريقة الباندوعان، وطريقة الصاراجان، وطريقة التشاور. التقويم في اللغة العربية في معهد أنوار الهدى لها أغراض كثيرة وهي لمعرفة كفاءة الطلاب في قراءة الكتب التراثية وعلوم الدين و فهم اللغة العربية، ولمعرفة فعالية استراتجية التعليم التي يستخدمها المعلم نضرا من طريقة ووسائل، ولمعرفة الصعوبات التي يشعرها المتعلم ومن هذه يمكن للملعم أن يطور الكتاب المستخدم، ولمعرفة ضعف الطلاب وقوتاه في حفظ المادة. والإختبار في معهد أنوار الهدى يـري مرتين، الإختبار لنصف الفصل الدراسي والإختبار الههائي. وهذين الإختبارين يختلفان في إجرائاتهما، الأول بطريقة قراءة الكتب والثاني بطريقة الإجابة في ورقة الإجابة أي الإمتحان التحريري. وأدوات التقيم التي تستخدم هي بنود الإختبار من متعدد، وبنود اختبار الصيواب والخطأ، وبنود الإختبار بالإجابة الموجزة.

اللاستفادة

يجب أن يكون تقييم التعلم استمرارية. هذا يعني أنها إذا تم اختباره في البداية بقراءة كتاب ، فيجب أن ينتهي أيضًا بقراءة كتاب. يكفي تغيير نقاط السؤال. الاستمرارية فى التقويم أهم بنسبة إعطاء النتيجة. وإجراء التقويم في المعهد يمكن تطبيقاته أكثر مرات بنسبة إجراءه في المدرساة.

المراجع

Asrul, Rusydi Ananda, and Rosnita. 2015. EVALUASI PEMBELAJARAN. Bandung: Citapustaka Media.

Asy'ari, Hasyim, and Ammar Zainuddin. 2018. 'Ta'līm Al-Lughah Al-Arābiyah Fi Al-Ma'had AsSalafi Wa Al-Ma'had Al-Hadīth Namūdzajan'. Izdihar: Journal of Arabic Language $\begin{array}{lllll}\text { Teaching, } \quad \text { Linguistics, } & \text { (2): } 167-80 .\end{array}$ https://doi.org/10.22219/izdihar.v1i2.7298.

Chairi, Effendi. 2019. 'Pengembangan Metode Bandongan Dalam Kajian Kitab Kuning Di Pesantren Attarbiyah Guluk-Guluk Dalam Perspektif Muhammad Abid al-Jabiri'. 
Nidhomul Haq: Jurnal Manajemen Pendidikan Islam 4 (1): 70-89. https://doi.org/10.31538/ndh.v4i1.233.

Mahirah B. 2017. 'EVALUASI BELAJAR PESERTA DIDIK (SISWA)'. Idaarah: Jurnal Manajemen Pendidikan 1 (2). https://doi.org/10.24252/idaarah.v1i2.4269.

Moh. Ainin. 2007. Metodologi Penelitian Bahasa Arab. Malang: Hilal Pustaka.

Muhammad Abd al-Khāliq. 1996. Ikhtibārāt Al-Lughah. al-Mamlakah al-Su'ūd al-'Arabiyah: 'Imādah Su'ūn al-Maktabāt.

Mu'izzuddin, Mochammad, Juhji Juhji, and Hasbullah Hasbullah. 2019. 'IMPLEMENTASI METODE SOROGAN DAN BANDUNGAN DALAM MENINGKATKAN KEMAMPUAN MEMBACA KITAB KUNING'. Geneologi PAl: Jurnal Pendidikan Agama Islam 6 (1): 43. https://doi.org/10.32678/geneologipai.v6i1.1942.

Nunung, Arifah, and Yustisianisa. 2012. Evaluasi Pembelajaran. Bandung: Mentari Pustaka.

Oktavera, Hasnil. 2019. 'Pembelajaran Bahasa Arab Sebagai Upaya Pembentukan Karakter Santri Di Pondok Pesantren'. Jurnal Ilmiah Iqra' 13 (1): 38-47. https://doi.org/10.30984/jii.v13i1.935.

Ridho, Ubaid. 2018. 'EVALUASI DALAM PEMBELAJARAN BAHASA ARAB'. An Nabighoh Jurnal Pendidikan dan Pembelajaran Bahasa Arab 20 (01): 19. https://doi.org/10.32332/annabighoh.v20i01.1124.

Rohman, Fathur. 2017. 'Pembelajaran Fiqih Berbasis Masalah Melalui Kegiatan Musyawarah Di Pondok Pesantren Al-Anwar Sarang Rembang'. Al-Tadzkiyyah: Jurnal Pendidikan Islam 8 (2): 179. https://doi.org/10.24042/atjpi.v8i2.2124.

Thoriqussu 'ud. 2012. 'MODEL-MODEL PENGEMBANGAN KAJIAN KITAB KUNING DI PONDOK PESANTREN'. Jurnal Ilmu Tarbiyah At-Tajdid 1 (2): 225-39. 
Tolinggi, Syindi Oktaviani R. 2020. 'Model Pembelajaran Bahasa Arab Di Pesantren Salafi Dan Khalafi: Studi Pebandingan Terhadap Pesantren Salafiyah Syafi'yah Pohuwato Dan Pesantren Hubolo Tapa'. Al-Lisan 6 (1): 64-95. https://doi.org/10.30603/al.v6i1.966.

Page | 186 Wulan, Elis Ratna, and Rusdiana. 2015. Evaluasi Pembelajaran. Bandung: Pustaka Setia. 